\title{
Statistical lives and the principle of maximum benefit
}

\author{
Albert Weale Department of Politics, University of York, York
}

\section{Editor's note}

In the allocation of resources to medical care society may tend to discriminate in favour of known individuals in present danger or distress rather than following a more rational strategy leading to improved average mortality and morbidity rates. The motives underlying this behaviour are examined critically.

In recent years there has developed a growing recognition that publicly financed health services need to utilise explicit principles of resource allocation. ${ }^{1}$ Policy makers have come to recognise this need in the light of evidence which suggests that increases in the supply of health services will be matched by an increase in the demand that is made upon them. Thus increasing expenditure on medical resources does not of itself solve the persistent problem of scarcity; resources will always be insufficient for the demands upon them. Combine this fact of scarcity with the acknowledgement that there are relatively efficient and inefficient ways of providing and delivering health services, and the need for explicit principles of allocation becomes plain. Yet the recognition of the need for principles does not of itself help us to develop such principles. The question still remains: on what basis should one allocate the limited resources that are available to health services in order to bring about an ethically acceptable allocation?

A particular example of this dilemma is provided by the problem of striking the correct balance between preventive and curative medicine. Thus, it has recently become fashionable to assert that available resources might be used to best effect if they were devoted more extensively to preventive measures - with the implication that they might be switched from the curative services. ${ }^{2}$ But the notion of best effect is left undefined in this context. What is meant by the assertion that preventive services are likely to be more efficient than curative services ? Efficiency in this context only has meaning in relation to a specified set of objectives. So in order to judge the claim that one use of resources is more efficient than another, we need to formulate a set of objectives in terms of which we can measure the performance, or output, of different types of services, or inputs.
In order to formulate these objectives it is neces- $\vec{\circ}$ sary that the community have a method for placing a value on the lives of its members. The manner in which the decision on allocating health services is made is then best pictured as follows. ${ }^{3}$ The com- $₫$ munity decides, by means of the political process, how much money is to be devoted to health services ${ }_{-}$ in total. This decision represents, in effect, the of community's evaluation of health services by com-음 parison with other desirable goods, like transport. facilities, education, defence and housing. Having made this decision, which in practice is usually little more than an incremental decision from previous years' expenditures, the public authorities must decide how best to use available resources. In the short term they may not have much room fore manoeuvre. Personnel will have been trained, 6 capital goods reacquired and revenue thereby committed. But in the longer term the public authorities should be seeking to move towards the most efficient use of resources possible, otherwise effort will be wasted and things left undone which ought to be done. What criterion should the public $\Rightarrow$ authorities use in making this decision on allocation ? A seductively attractive, if ambiguous, proposal in? this context is that, in their health expenditures, theo public authorities should seek to maximise the value of lives saved or prolonged.

This decision-making process in practice begso the question of what value the community assigns. to the lives of its members. What typically emergeso from the process is the goal simply of maximising the number of lives saved or the average length of life for members of a given population. Thus the widespread use of population mortality rates or standardised mortality ratios in the appraisal of health service performance provides a measure of effectiveness only on the assumption that what is of interest is simply the number of lives saved or thew numbers multiplied by the increases in average length of life. ${ }^{4}$ No differential value is attached too the lives of different persons. Each is counted foro one and no one for more than one. The criterion has ${ }^{\text {? }}$ in fact a certain ethical attractiveness to it. Because lives are weighted equally there will be no deliberate bias or discrimination involved in the selection on treatment of beneficiaries from the health services $\stackrel{\mathbb{Q}}{\varrho}$ Moreover, provided the technical problems can beg solved in estimating the effectiveness of various? forms of service, that is provided what economistso 
call the relevant production functions can be determined, the criterion will yield specific instructions as to the manner in which available resources are to be used. Finally, the criterion will be consistent with, and may perhaps be taken as an expression of, the ideal of communal or social responsibility for the natural contingencies of illhealth and misfortune. Satisfying the conditions of impartiality, determinateness and social solidarity, the goal of maximising the effectiveness of health services by reference to the number of lives saved or average length of life promoted may seem an attractive aim, not least because it is a practical possibility to emerge from the political process. I shall call the criterion in this form the principle of maximum benefit.

\section{The principle of maximum benefit}

How might this principle be applied ? An example is provided by Correa's discussion of the optimal allocation of resources for the treatment of an epidemic of whooping cough in Northern Santiago, Chile, in $1963 .{ }^{5}$ In his discussion, Correa assumed that the general objective of the health services in response to an outbreak of whooping cough was to minimise the number of deaths. The resources available could either be used to help cure those who had already contracted the disease or they could be used in preventive measures for the population at risk. If resources employed in treatment are more effective in minimising deaths, then all available resources should be devoted to treatment; and similarly, if prevention is more effective than treatment, all resources should be put into prevention. Using data from the Pan American Health Organisation, Correa argued that the effectiveness of prevention was considerably greater than that of treatment. So much so in fact that, whereas with resources split between prevention and treatment only an estimated 124 deaths were avoided, the number of deaths to be avoided by completely switching resources into prevention was an estimated 470 . Naturally there is no reason to assume that the identity of the persons whose lives were saved would have been the same had the switch been made. Nevertheless, an extra 346 deaths could have been avoided. The principle of maximum benefit would enjoin that the switch be made; it implies a maximising strategy.

\section{The ethical appeal}

A number of writers assume in situations of this kind, where there are limited resources with different sized groups of persons in competition for them, that the principle of maximum benefit has an obvious and intuitive ethical appeal. In an imaginary but nevertheless similar example, Philippa
Foot $^{6}$ claimed that it would clearly be right to save the lives of the larger group of persons. However, it can be argued that this ethical intuition is not as ? well-grounded as at first sight it appears. One $\underset{\vec{D}}{\vec{D}}$ important type of counter-example to the intuition $\frac{0}{0}$ was first identified by Calabresi, and has been discussed by several writers subsequently. ${ }^{7}$ Calabresi $\frac{\bar{D}}{\bar{D}}$ pointed out that there are many instances in which $\frac{\vec{D}}{\vec{\phi}}$ society does not act on the principle of maximum $\propto$ benefit. In particular there are situations in which of more value is placed on rescuing known lives in $\overrightarrow{0}$ present danger than would be placed on saving the $\overrightarrow{\vec{H}}$ unknown, future lives of persons distributed, as $\overrightarrow{\mathcal{O}}$ statistics, among the population at large:

$\ldots$ in the uncustomary case of an individual $-\mathbf{a} \stackrel{\mathbb{Q}}{G}$ known individual rather than a statistical un- $\rightarrow$ known - in a position of life or death, we are apt to $\vec{\infty}$ spend very much more to save him than in any con- of ceivable money sense he is worth. And while I do $\frac{\text { ㅇ }}{2}$ not doubt this is as it should be, it seems odd that $\vec{\nabla}$ we should refuse to apply the same standards of $\mathbb{D}$ 'value beyond any price' when we deal with the $\overparen{\Phi}$ same man's life as part of a statistic. But odd or not, $\frac{7}{8}$ it is the case. ${ }^{8}$

Calabresi in this passage makes two assertions: $\vec{\theta}$ that there is a systematic inconsistency in the value which is assigned to life in specific circumstances, and that this inconsistency is ethically defensible. The 'statistical lives paradox' is just this latter assertion. Society, the argument runs, is quite correct in preferring to spend large sums on the $\stackrel{\unrhd}{\perp}$ rescue of lone yachtsmen, trapped miners and $\overrightarrow{\vec{A}}$ candidates for heart transplants or renal dialysis $\frac{\rho}{3}$ than expending the same resources on more mundane and anonymous services which would be justified by application of the principle of maximum benefit. So in stipulating as maximand the mini- $\overline{\mathrm{D}}$ misation of mortality, intending to provide an $\frac{0}{3}$ objective in terms of which health services performance could be measured, we already seem to $ᄋ$ have hit an ethically controversial formula.

\section{The element of doubt}

The force of Calabresi's counter-example to the principle of maximum benefit has been questioned on various grounds. One type of reason for doubting $N$ its force derives from instances of policy where $N_{\omega}$ known present lives are not favoured at the expense 0 of unknown statistical lives. For example, in one 6 discussion of the ethical risks attached to the $\overparen{D}$ totally implantable artificial heart, one panel $\stackrel{\infty}{+}$ rejected the use of Plutonium-238 in powering the $T$ device in part because it involved the dangers of $\frac{\vec{D}}{\Phi}$ radiation to unknown but statistically significant $\stackrel{\Phi}{\Phi}$ sectors of the population. ${ }^{9}$ In this instance it seems $\stackrel{\mathbb{Q}}{\stackrel{Q}{2}}$ that a smaller number of future statistical lives were $\overline{0}$ being preferred to the lives of those who would be known to benefit. But one such example of this type 
does not really call into question the statistical lives paradox. It is sufficient for the paradox that there exist some inconsistencies in the implicit valuation of lives in different circumstances, not that there be such inconsistency in every conceivable circumstance. Moreover, attitudes towards the use of nuclear energy in many of its forms are so complex that an example drawn from an application of nuclear techniques is perhaps not the most uncontroversial that could have been chosen.

A more serious objection to the force of the paradox is to say that the circumstances in which the smaller known persons are preferred to the larger unknown group are so special as not to be generally significant. ${ }^{10}$ No general policy inferences are to be drawn from the fact that sometimes members of society do seem inconsistent in the value they place on human life. But, unless some further reason can be given for distinguishing the instances in question, this does not solve the theoretical problem that the statistical lives paradox seems to provide a counterexample to the principle of maximum benefit. If all that distinguishes the relevant instances is that they are just the cases in which especially high value is placed on human life, the paradox is not resolved but heightened. Moreover, the inconsistency in question is not always simply accepted by society. Thus a major catastrophe often seems to act as a catalyst for public authorities to take action on preventive measures. ${ }^{11} \mathrm{~A}$ small number of lives lost seems to dramatise the inconsistencies in question, and so lead to pressure to reduce them. So, it does not seem to be a simple task to dispose of Calabresi's counter-argument to the wholesale application of the principle of maximum benefit. Is there a satisfactory way of dissolving the paradox, either by demarcating clearly those instances where the principle of maximum benefit does not apply or by undermining the bias in favour of the non-maximisation strategy? Before seeking to answer this question, I shall first aim to clear up one or two problems in the formulation of the paradox itself.

\section{Social evaluation of life}

Calabresi's formulation of the paradox places the problem in the broadest context of the social evaluation of life. The notion of social evaluation does very general service in this framework, covering instances where governments do not impose stricter conditions on independent activities, for example not increasing the legally required minimum depth of tyre tread, cases where governments fail to supply certain benefits, for example replacing a level crossing by a bridge, and instances where governments take positive action, for example by rescuing lone yachtsmen or providing facilities for organ transplants. Each of these cases is supposed to represent a form of social evaluation of life. The problem for Calabresi is how far and in what ways these different evaluations are, and ought to be罗 consistent with one another. ${ }^{12}$

To pose the problem in this way is, however, to ? put the issue into too large a context. There arê弓 many reasons why evaluations might not be con $=-$ sistent with one another when considering these veryo diverse situations. Policy making within publien organisations is constrained by uncertainty and theo limits of time which prevent departments of state from co-ordinating with one another. For analytices purposes it may be convenient to think of the $\vec{D}$ government as a 'unitary being' ${ }^{13}$ with a consisten set of goals, but one should not be surprised at empirical evidence which is inconsistent with this assumption. We should only look for consistento social evaluations of life in specific contexts. More $-T$ over, to ignore the specific is to risk losing sight of important distinctions. Thus it may be importanter to distinguish between the risks which society allows individuals to run, as when it fails to impose more stringent safety regulations for private cars, and the evaluation of life which is implied by governmento action in providing health services. Reasons of anti-paternalism may suggest at times that the government should allow certain risky activities, despite the relatively low evaluation of life this might imply; reasons of public responsibility on the other hand may dictate relatively high standards of safety in the services which governments supply? In other words, if we look at the issue in the broadesto context, we may be confusing problems in thes consistency of the social evaluation of life with countervailing considerations which would dis $\overrightarrow{\overrightarrow{0}}$ tinguish cases which superficially look alike.

For this reason it is better to examine the problem? of statistical lives not in the context of all the life? saving activities that governments might undertake but rather in the specific context of the supply of health services. Examples here might be of the sort discussed by Correa and Foot, where it is a matter of deciding whether available resources should be usede either for those who have already contracted an otherwise fatal disease or instead for a larger number? of unknown statistical persons. On the other hand they might be more general in scope, where it is a․ matter, for example, of deciding between investment in casualty units or in preventive medicine. But it seems to me to be important to limit in this way the scope of the argument to allocational decisions with $-\mathrm{w}$ in health services, since in such cases one is dealing with a fundamentally homogeneous set of decisions 6 how should one determine the correct balances between different types of health service provided ${ }^{+}$ publicly?

\section{Hypothetical example}

In order to see why, in this context, any stratege other than the maximising one seems paradoxicalo consider the following arrangement. Suppose it is 
known by members of a community that there are different ways in which health services may be supplied. Suppose also that the community health budget has been fixed, so that the choices available to members of the community consist simply in the exercise of a preference over relatively efficient or inefficient forms of services. If each member of the community has a vote about which package of health services to choose, it will be prudent for each individual to vote for the most efficient service, provided certain conditions are satisfied, because in that way they would be maximising their own chances of survival. Similarly, to take a specific example, in the allocation of resources for the control of whooping cough, Correa's instance, guardians responsible for the interests of children who were likely to contract the disease would be prudent to choose the preventive strategy before the epidemic broke out, because in that way they would be minimising the mortality risks of those for whom they were responsible. So, the reason why the nonmaximisation strategy seems paradoxical is that it is contrary to the strategy that prudent individuals would choose for their community if they were protecting their own interests, or the interests of those for whom they were responsible.

In fact things are a little more complicated, because the supposition abstracts from the distribution of health risks in the community. Some people may be especially prone to particular forms of ill-health, in which case they might be prudent in voting for a health system that was less efficient overall because it concentrated facilities in certain specific areas. Young motor cyclists for example have an interest in voting for the over-supply relative to the demands of the population at large of casualty units. This sort of bias can be eliminated in part by noting that uncertainty reduces a person's interest in the distribution of risks. If one is unsure of one's future place in the scheme of things, so that one has no reason for projecting one's present needs into the future, then the maximisation strategy will still be prudent, despite one's present concerns. Thus uncertainty about the distribution of risks may make it rational simply to concentrate upon the average level of risks. It also provides some justification for the common practice in cost-benefit analyses of the value of mortality reductions by which individual's benefit is equated with average benefit. ${ }^{14}$

The attractiveness of the principle of maximum benefit, therefore, consists in its being the principle upon which prudent and self-interested persons would converge, if they had to make a decision on the allocation of health services before they knew which particular form of ill-health they would suffer. Against this argument, is it possible to provide any reasons of ethical principle which would favour the non-maximisation strategy and rationalise the preference for known lives in present danger?

\section{Looking for the answer}

In seeking to answer this question, it will be useful to dismiss three possible lines of solution.

The first possible justification for preferring known lives in present danger is simply that the future is uncertain. If we know that good can be done now we should take the opportunity when it presents itself. The effect of this argument is to suggest that sometimes the maximising strategy entails saving known lives in present danger, because the number of future lives that might be benefited should be discounted on grounds of uncertainty. However, unless we are extremely pessimistic about the future, there is no reason to assume that we can always reduce the future expected number of lives saved below the figure for known present lives. Without further reasons for reducing our estimates of future expected benefit, we should be engaged in a process of double discounting. ${ }^{15}$ Moreover, our confidence in treating persons whose life is known to be in present danger is subject to uncertainty, though of a less intense kind. Estimates of the effectiveness of various treatments are based on past performance, and there may be a problem of inferring from past to present efficacy. So, although the maximising strategy may on occasions enjoin us to prefer the known and present to the unknown and future, there is no reason for holding that this will always be so.

A second possible justification for preferring the present aid strategy also relies on the fact that it is sometimes entailed by the maximisation strategy. Situations of present danger often call forth extra resources in the form of voluntary aid, which might not otherwise be available. This factor is perhaps more evident in dramatic rescue situations, for example a group of miners trapped down a mine, than it is in strict medical situations. But one can imagine more volunteer nurses, for example, coming forward to help nurse the sick in an epidemic than might be forthcoming as auxiliaries in the rather mundane tasks of a vaccination programme. Even so, this argument is insufficient to justify a general preference for the present aid strategy. It suggests rather that when seeking to estimate the relative effectiveness of different programmes, one should be careful to do the accounting correctly, so that all available resources are taken into consideration. ${ }^{16}$

Between them these two arguments appear to cover all the reasons for preferring present rescue because it is present. A third reason which might be advanced is that of 'pure time-preference', the residual preference for the present merely because it is present. It has long been noted that there is a human 'telescopic faculty' which tends to enlarge the value of present satisfactions by comparison with future satisfactions. ${ }^{17}$ Pure time-preference 
in this sense is mere temporal chauvinism however. It cannot function as a rational consideration in decisions on the allocation of life-saving resources.

In the place of these three arguments we need an argument for the present rescue strategy which establishes at least the conclusion that saving a greater number of lives rather than a smaller number is not morally preferable. In effect we need an argument that numbers should not count, nor count decisively, when allocating medical resources. One approach along these lines begins by taking seriously the difference between individual and social decision-making. It asserts that whereas individuals have goals, whose attainment it is sensible for them to maximise, society has no such collective aims. Social organisation is not about achieving some aggregated collective good, but is rather a matter of providing the space and freedom within which individuals can pursue their own self-determined ends. Although a maximising decision procedure is appropriate for individual choice, it will not be applicable to social or collective decision-making. Social responsibility on this view is restricted to maintaining individual rights. Provided these rights are enforced the responsibilities of public officials are discharged.

Now it is a characteristic feature of the concept of an individual right that it limits severely the ways in which a person may be treated in order to bring about some desirable collective goal. ${ }^{18}$ For example, if innocent persons have the right to freedom, it would violate their rights to frame charges against them and so deprive them of their freedom, even if this were necessary to provide for the safety and well-being of the population at large. Utilitarianism contrasts with a rights theory precisely at this point. It allows significant individual interests to be sacrificed in order to attain collective benefits, despite the fact that the collective benefits in question are relatively insignificant for each member of society, because the sum of these individually insignificant benefits may outweigh the loss of significant benefits to a particular individual or group of individuals. This is the burden of the charge, for example, that under certain circumstances utilitarianism would license slavery.

What bearing does this characteristic feature of rights have on the statistical lives paradox ? Suppose we interpret health service provision as one means by which the government maintains the right to life. ${ }^{19}$ This right should be interpreted as a claimright, in Hohfeld's sense. ${ }^{20}$ That is to say, the right to life of person $\mathbf{A}$ implies that others have a duty to refrain from engaging in actions leading to A's death and also a duty in appropriate circumstances to provide $A$ with aid should he be in a position where death is threatened. Where there are two needy groups, however, whose members have their right to life threatened, it can be argued that the relative sizes of the two groups is immaterial to the appraisal of the correct course of action. Just as the notion of a right prevents an aggregate benefie leading to the sacrifice of a significant individual: interest, so it also precludes the idea that thes claims of a more numerous set of right-holders should automatically outweigh those of a less을 numerous set. Within the theory of rights there is? no principle of aggregation: it makes no sense within the theory to say that failure to satisfy the claimrights of two persons is twice as bad as failure in respect of one. Put another way, no one in the larger group is wronged if the rights of the smaller group are preferred, in a way in which they would? be wronged if there were no conflict of rights and aid were available to save them but not used through negligence. ${ }^{21}$ Precisely because a theory of $\triangle$ rights is intended to prevent the claims of in $\overrightarrow{-\infty}$ dividuals being swallowed up in the claims of larger numbers of people, the members of the largers group have no grounds for complaint if the claim- $\overrightarrow{-}$ rights of the smaller group are satisfied instead.

As an argument for this point of view considern the following imaginary case. Suppose the choice were between saving the life of one person, or adding just one day to the life of everyone else in $\overrightarrow{0}$ the community. I doubt that many people wouldot choose the aggregated advantage, despite the totat of the extra days to be lived being greater than theo extra length of life that would accrue to the individual. This unwillingness is part of the force of the concept of individual rights. But now suppose that the collective benefit were increased to two days per person. Could that make it right to prefero the larger to the smaller set of persons ? It seems not. For anything that would serve to make it right in this second case is already present in the first Already there is an established inequality of benefit. So the relative ordering of individual and collective benefit is not altered. Perhaps though the increasing magnitude of the difference alters our moral judgement ? However, this is implausible. Suppose that5 there were a morally significant difference of magnitude. Let us say that $\mathbf{x}$ days is the difference of magnitude that is barely morally significant. Byo definition $x-1$ days will not be morally significant. Saving $x-1$ days of life for each member of theor community will not be sufficient reason for failuren to save the life of one person. But, if this is accepted, N it means that the addition of two morally insignifi- cant magnitudes amounts to a morally significant difference. Yet if neither counts as significant in itself, it is difficult to see how both together could. ${ }^{22}$ ?

The effect of these arguments is to establish how difficult it is within a rights theory to incorporateo the idea that numerical differences among those affected by an act imply a moral difference. An alternative, but complementary, way of looking at the matter is to note how, as a matter or logic, the ascription of rights to persons allows themo discretion to prefer their own interests to the equally? 
significant, or perhaps more significant, interests of others. As conventionally construed, for example, A's right to life does not imply that others should give up bodily organs to maintain A's right. B might quite properly prefer to retain one of his kidneys, even when its donation would not cause him harm, rather than save A's life. (If this were not so, compulsory organ transplants would be quite in order.) Similarly, B may quite properly prefer to save his own life instead of the lives of a large number of As. If this were not so, laying down one's life when needful for the benefit of others would cease to be a matter of supererogation, and become a matter of duty. So if B can properly prefer his own life to that of a number of others, why cannot another agent take up B's point of view and prefer to save B's life rather than the lives of a large number of others ? ${ }^{23}$

One way of precluding the possibility that a third-party can take up an individual's viewpoint in preference to that of a large number of other persons is to claim that B's reasons for acting within his rights are agent-relative. Only B can have reasons for preferring his single life to the lives of a large number of others. ${ }^{24}$ If this is true, it needs to be explained how it is so. The answer, I conjecture, is that considerations of right do not exhaust the whole of morality. We must also leave room for the concept of the good, and for what it would be better on the whole for an agent to do within the constraint of right. ${ }^{25}$ Thus it may not be wrong for individuals to prefer, within their rights, their own interests to the equally significant interests of a larger number of other people; but it does not follow that it would be better for a thirdparty to act likewise, when he could save a greater number of lives. And although it might not be wrong, as such, to save the life of an individual in preference to the larger number of lives of the members of a community, it does not follow that it would be better on the whole to prefer the life of a single individual to the lives of a larger group of persons. To point out that nobody is wronged by a preference for the smaller set is essentially to say that there are no reasons of right which enable us to discriminate the moral worth of situations where rights which are of equal importance to their holders cannot simultaneously be maintained. Other grounds may exist, however, on which we can discriminate the moral worth of such situations. It may simply be better on the whole to favour the larger set of persons. What, though, can we mean by this statement?

\section{The maximising strategy}

To answer this question, let us revert to the argument designed to explicate the statistical lives paradox and support the maximising strategy. The maximising strategy is justified by appeal to the argument that its use increases the average life- $-\frac{\text { T }}{=}$ expectancy of all persons in society. It would be prudent, or rational, therefore for everyone to consent to an arrangement by which the publicos authorities selected the most efficient pattern ofo health services in respect of this goal. Of course it흠 will not be rational for someone whose life is cur- $\frac{\bar{p}}{7}$ rently in danger to consent to the maximising $\mathbb{Q}_{\square}$ strategy if that implies he should be left to die. But, it may be argued, that is just the wrong point of view from which to look at the issue. Even lowered? average mortality statistics have to show up as $\vec{\omega}$ actual deaths somewhere, and it is hardly surprising ? to find that the place where they show up is not $\overline{3}$ the place at which to find assent to the maximising or strategy. What people whose lives are in peril want + is present help. Yet that fact does nothing to show $\vec{\infty}$ that on balance it is better that help should be provided. To suppose the contrary is to suppose there is no balancing to be done. Ex hypothesi, $\vec{D}$ there is.

So my suggestion is that the judgement, 'On $\mathbb{\Phi}$ balance it is better to act according to the principle 3 of maximum benefit' should be understood as an hypothesis about the sort of arrangement to which $\vec{\varphi}$ it would be rational for people to consent at any $\overrightarrow{0}$ given level of expenditure on health services. Since it would be rational to assent to the lowest average level of risk, the principle of maximum benefit is judged to be the rule which on balance it would be better to follow. Consequently it will be better on $\frac{O}{D}$ balance if resources are not deployed or made $\varrho$ available in certain contingencies, if they could be $\overrightarrow{\vec{O}}$ more effectively used elsewhere.

Two points should be made about this mode of argument. In the first place it is not being claimed that there is any actual consent, even of the tacit $\bar{\beta}$ variety, on the part of persons which obliges them to adopt the maximising strategy in consequence. 3 Consent here does not figure as in legal obligation, where one may be obliged to abide by the terms of $\frac{\mathrm{O}}{3}$ a contract one had agreed because one has induced reliance in others on one's future conduct. Instead ? it figures in an analysis of what it means to say that $\frac{D}{0}$ it is better to save the lives of the larger of two groups of persons. The meaning is, then, that $N$ everyone gains by running an increased mortality $N$ risk in some situations - no nearby unit in the case $N$ of rural road accidents - because their loss in this $\omega$ respect is more than counterbalanced by gains elsewhere - improved vaccination programmes or whatever.

The second point to be made is that agreement ? to the maximising strategy has in some sense to be $\overrightarrow{0}$ a 'rational' choice. Not necessarily the choice that $\mathbb{D}$ people would make, just as they are in themselves, $\frac{O}{\mathbb{D}}$ but the choice that it would be prudent to make. There is nothing arcane about this concept of rationality. It excludes a positive preference for 8 risk-taking in respect of one's voting decision on 
health services, but in context that does not seem so outlandish. Life is assumed to be a good, the more of which you have the better. Prudence suggests that the best way to continue living is to vote for an allocation of resources which minimises one's mortality risks, consistent with those activities you wish to undertake.

One obvious objection to the rationale of the maximising strategy is that it would seem to license the survival lottery, which is similarly aimed at increasing one's life expectancy. ${ }^{26}$ The survival lottery aims to replace the natural lottery which distributes fatal illness among the population by an instituted lottery which redistributes these natural contingencies. Although a piece of medical science fiction, it does raise an interesting point of principle. Suppose organ transplants were developed to the point where almost any vital organ could be transplanted from any one person to any other. Individuals might find it in their interests to join a survival lottery in which one person consented to give up his life so that his organs could be redistributed among those in need. This arrangement might serve to raise average life expectancy, though it would do it in a way that imposed an increased mortality risk in respect of suddenly being forced to be available as a donor. Nevertheless might there not be situations in which it would be prudent, in the sense above, to join a survival lottery? If so, we would be doing more good than harm to institute one. This conclusion, however, might seem to be just the reductio ad absurdum for for the previous argument. If the prudence of reducing mortality risks leads to the survival lottery, someone might say, then this merely reveals the fallaciousness of seeking to use an hypothesis about prudential choice to support one allocation of resources rather than another.

\section{The survival lottery}

In order to preserve the original argument, therefore, we must drive a wedge between the survival lottery and the maximising strategy in the case of statistical lives. Fortunately we can do just this. In the first place, the survival lottery provides no incentive for individuals to take care of their own health. ${ }^{27}$ Any nationalised health system is likely to exhibit a compromise between the principles of individual responsibility and social solidarity, simply because it rests on the assumption that the financial risks of ill health should be borne by the community at large. However, the survival lottery extends this principle beyond financial risks to bodily integrity. In so doing it provides individuals with no natural penalties for the indulgences of contemporary living - overeating, drinking and smoking - to which modern flesh is heir. By his style of life an individual places an implicit evaluation on his own life. Someone who has a higher evaluation of his own life might well hesitate to $\stackrel{T}{F}$ join a survival lottery because the benefits of his own efforts to remain fit could be dissipated among those who placed a lower evaluation on their own o? lives. Average health under such a system becomes 0 rather like a 'public good', such as clean air or uncongested roads, from which everyone benefits, $\frac{\bar{m}}{\vec{D}}$ but towards which, as is well-known, no one has $\stackrel{\mathbb{Q}}{\Omega}$ an incentive to contribute. ${ }^{28}$

There is, however, a further reason why one should distinguish the survival lottery from the $\stackrel{\circ}{\circ}$ maximising strategy. The maximising strategy in- $\overrightarrow{\vec{\omega}}$ volves a failure to take aid to some persons because $\stackrel{\mathscr{S}}{S}$ the resources so consumed could be more effectively used elsewhere. By contrast the survival lottery of involves not simply a failure to render positive aid $\rightarrow$ but a deliberate taking of an individual's life. So, it $\vec{\phi}$ can be argued that the prohibition on taking life $O$ fell within the sphere of principles of right and involved an absolute prohibition, whereas the giving $\vec{D}$ of aid to persons fell within the sphere of the good $\mathbb{D}_{\mathbb{D}}$ where relative advantages have to be weighed. In $\varnothing$ Ross's terms the prohibition upon taking life is a duty $\vec{z}$ of non-maleficence, which is more stringent in char- $\stackrel{\Phi}{-}$ acter than the duties of beneficence including the $\vec{\varphi}$ duty of rendering aid to save life where more than minimal effort is involved. ${ }^{29}$ The principles of right lay down minimal standards which must not be breached; principles of the good specify ideals which it would be morally desirable to obtain. ${ }^{30}$ o If this distinction can be maintained, it would $\stackrel{0}{\varnothing}$ provide an important criterion for distinguishing $\cong$ the maximising strategy from the survival lottery. $\vec{\overline{ }}$ Moreover, there are the other differences between 3 negative and positive duties as noted by $\mathrm{Trammell}^{31}$ : negative duties may all be discharged, whereas this is not true of imperfect positive duties; the failure to perform an imperfect positive duty often leaves other people the scope for performance; and the 3 distinction allows scope for the principle of responsibility. Finally and in addition the public $\stackrel{\circ}{\jmath}$ finance of a health service suggests that it is basically a scheme of mutual aid, for the benefit of its participants, so that it rests more on a conception of $\frac{7}{2}$ the good than of the right.

Even duties of non-maleficence may be over- $N$ ridden by consent or where the principle 'ought $N$ implies can' does not apply (so I would assert in my N non-paternalistic way). So, in certain circumstances, $\sigma$ the survival lottery, or something like it, may be morally permissible. An instance here would be in cases of an overfull lifeboat, where some persons $\stackrel{\oplus}{\Phi}$ must leave the lifeboat in order for anyone to survive. Thus in the decision of United States v. Holmes $^{32}$ it was argued by the judge that Holmes, $\mathbb{D}$ the senior seaman in charge of a life-boat, should $\frac{\AA}{\mathbb{D}}$ not have taken the decision to jettison fourteen $\varrho$ passengers, but should instead have used a randomising device to decide which of the survivors should 8 be ejected from the life-boat. The judgement in this 
case is presumably that it is better on balance that the lives of some people should be sacrificed, in order that most people should have an increased chance of rescue. I do not know of any real life medical parallels, where it is necessary to take some lives in order to increase the chances of survival for a larger number of other people. If there are parallels, however, I would suggest that principles of the good were to be invoked only where situations were so extreme that a prima facie case existed for suspending the application of principles of right.

Even in such cases, however, it may only be morally permissible to ignore the constraint of right. In an English case similar to that of Holmes, Regina v. Dudley, ${ }^{33}$ the judge argued that all persons should wait together, either to be saved or to lose their lives. The inviolability of the right to life is here taken to preclude persons protecting themselves by instituting, against an individual's will, a survival lottery. This point may be expressed in our framework by saying that it is not sufficient to rely on hypothetical, rational consent as justifying the survival lottery. Instead one must have the actual consent of all of the participants. Potential participants would be within their rights, on this argument, in refusing to participate in a survival lottery, even though the consequence might be not simply their own death but that of a large number of other people as well. Obviously a choice has to be made here concerning the stringency with which the right to life is interpreted. But, however stringently the right is interpreted, it must still remain a negative right of non-interference. As such it contrasts with the positive right to (more than minimal) aid, whose application depends on principles of the good and a judgement about what it is better on balance to do.

\section{Satisfying the need for personal care}

So far I have sought to justify the maximising strategy in terms of its propensity to bring about on balance more good than harm. The principle of maximum benefit is applicable, precisely because the principles of right do not enable us to distinguish between greater and lesser numbers. But it could be argued that there is one type of consideration which is left out of account in this approach. The original choice was between a smaller number of present known lives in danger and a larger number of future unknown lives. Suppose we accept that temporal difference is immaterial and numerical difference favours the maximising strategy. There is still the difference between a group of known individuals and a group of unknown individuals. It is a characteristic feature of maximising ethical theories that they give no weight to personal ties and relationships: the most famous example of this flaw is provided by Godwin's argument that in a choice between saving the life of a relative and saving the life of Archbishop Fenélon one should save the latter because that action was? more fecund. ${ }^{34}$ So it might be argued that our approach has built into it an assumption of im-? personality which was inappropriate in the case of medicine. What matters it might be argued is tha a doctor should treat his patients in a manner that? is most suitable to their needs; it is not his task to be concerned with some overall optimal allocationes of resources.

We can put the point as follows. We have noted already that the rendering of aid is a positive duty $\vec{\omega}$ For medical personnel it is the duty of rendering? aid within their competence and up to the limits that can reasonably be expected within the com-ir munity. They do not have the further, or second-i order, duty to make sure that they will always be inoo the best position possible to fulfil their primaryo duty. So, if a doctor is confronted with patients known to him who are in need, it might be argued that his primary duty is to those patients and noto to a set of statistical unknowns. Moreover, were a doctor to take into consideration the well-being of unknown persons, he would be in danger of vio- lating certain crucial elements in the relationship $\overrightarrow{0}$ with his patients. Individual concern and mutualco trust would be impossible because they can onlyo arise in a relationship where the patient can rely on the doctor to treat him in accordance with his present needs. To use Fried's ${ }^{35}$ analogy: certaing principles 'score' relationships, just as a musicalō score is a constitutive element in the performance of a piece of music. Unless those principles are present, certain relationships are impossible.

This is a powerful argument, but its implications are unclear. In the first place its force in respect of some cases is irrelevant. The curing relationship need not always be personal. If the allocational:choice, for example, is between casualty unit to 3 . cope with motor accident victims and a preventive screening programme, there is no reason to think that the relationship between doctor and patient is 0 more personal in the one case than in the other. More importantly, it might be suggested that whato the argument really implies is that allocational $\bar{N}$ decisions should be taken at a level which is quite? distinct from that of the doctor-patient relationship. N Thus one implication might be that national and area administrators ought to be primarily responsible 0 for allocating resources because they are less likely ${ }_{0}$ to be subject to the pressures of the personal than $\stackrel{D}{\triangle}$ doctors in a client-doctor relationship. Doctors $\stackrel{\oplus}{\rightarrow}$ would lose considerable clinical freedom to prescribe 0 certain expensive courses of treatment, because $\overrightarrow{0}$ administrators would ensure that the resources $\stackrel{\mathbb{D}}{\Omega}$ were not released to make such treatment available. $\frac{\overrightarrow{\mathbb{D}}}{\mathrm{Q}}$ Fried himself suggests a similar distinction between $\frac{\Omega}{O}$ administrative and medical personnel in respect of randomised clinical trials. ${ }^{36}$ The administrative level $ᄋ$ would be responsible for selecting patients for 
RCTs, and 'double-blind' trials would be used, to prevent doctors as well as patients knowing which 'real' course of treatment was being followed. In this way the complicated considerations which arise in relationships between known persons would be avoided.

For the advocate of the principle of maximum benefit this division into levels of decision-making, with considerations of optimal allocation only entering in at the administrative level, may be desirable in itself. After all, the maximising strategy must be introduced within the limits of the practically feasible. Just as an earlier generation of utilitarians thought of the principle of personal responsibility to be practically the best way of achieving the maximum attainable level of social welfare, ${ }^{37}$ so the practice of doctors concentrating on doing their best by their own known patients, but within allocational limits that have been administratively determined, might be just the best way of implementing the principle of maximum benefit. In other words, if the personal element of medical care interferes with a prudent allocation of resources, it may be better to have those who are not personally acquainted with the recipients taking the allocational decisions.

Moreover, the personalist argument is vulnerable at one crucial point. The principles which are taken to score certain relationships can only be made intelligible in terms of the attitudes and expectations which the parties involved bring to that relationship. Public attitudes may well change towards the rationing role of the doctor, and Kendall ${ }^{38}$ may well be right in suggesting that the public is capable of appreciating the implications of scarce medical resources for the conduct of doctors. Perhaps therefore the scoring of the relationship between doctor and patient will change. In so far as it does, the direction of change looks as though it will support the principle of maximum benefit.

\section{Conclusion}

I have tried to argue that the statistical lives paradox can be eliminated only by supposing that the principle of maximum benefit is productive on balance of greater good than the alternative of favouring known lives in present danger. As such the statistical lives paradox presents no objection, in principle, to shifting medical resources in a more efficient direction. Nothing in what I have said implies a particular view about what would be a more efficient direction. Although great expectations are held out on behalf of preventive medicine, one should remain agnostic until the case is demonstrated one way or the other. Perhaps an efficient allocation of resources, as measured by mortality rates, would dictate that preventive medicine be given greater priority relative to curative medicine. Perhaps not. All I have sought to establish is that at least one supposed ethical barrier to an efficient $\underset{+}{+}$ allocation is not as compelling as some have sup- $\overline{\bar{n}}$ posed. There is nothing right in itself or good on balance about discriminating in favour of known $\stackrel{\vec{F}}{\vec{N}}$ lives in present danger, if greater efficiency can be $-\overrightarrow{0}$ achieved otherwise.

Having come to that positive conclusion in $\frac{\bar{C}}{\bar{c}}$ favour of the principle of maximum benefit, $I \vec{\otimes}$ should like to conclude by noting what I take to be the major ethical difficulty with its implementation. क As I have noted, minimising average mortality risks $\vec{\circ}$ at any given level of expenditure implies no view $\overrightarrow{\vec{A}}$ about the distribution of those risks. It is possible ${ }_{\sigma}^{\omega}$ that maximising the effectiveness of treatment may $\overline{\bar{z}}$ increase inequality as between diseases or causes of $\Phi$ mortality, social classes or income groups, age- $r$ groups, the sexes and the regions. Nor need the $\vec{A}$ movements in respect of different types of in- $c$ equality be consistent with one another. For $\stackrel{\circ}{\triangle}$ example, inequality of risk between disease cate- gories may decrease, though social class inequalities $\nabla_{\mathbb{D}}$ may increase. Despite these complications there is $\overparen{\Phi}$ no reason why the distributional implications of the 3 allocation of medical facilities should be ignored, $\mathbb{\Phi}$ any more than an increase in national income $\overrightarrow{0}$ achieved only with a less equal distribution should always be regarded as beneficial. I have argued that abstracting from the distribution of risks it would be prudent for persons to favour the maximising strategy. However, someone might hold to a distributive principle by which average gains had to be weighed against distributional considerations. $\unrhd$ In terms of the present argument this would mean $\overrightarrow{\vec{O}}$ that even prudent persons might find it impossible 3 to converge on an agreed system of allocating health resources. I have left any mention of this? difficulty until the end because $I$ am unconvinced that a great deal of theoretical value can be said on it. In the end a political theorist may simply be in the position of pointing to the possibility of value conflict whilst acknowledging that only the political O process can reconcile conflicting interests into an acceptable, if not ideal, social policy.

\section{Acknowledgement}

The author thanks Susan Mendus for a number of useful discussions on the topic of this paper.

\section{References and notes}

'See the following selected from a long list: Cochrane, $\stackrel{\mathscr{S}}{+}$ A L (1972), Effectiveness and efficiency: Random 0 reflections on health services, Nuffield Provincialo Hospitals Trust, Oxford; Cooper, M H (1972), $\overrightarrow{\mathbb{D}}$ Rationing health care, Croom Helm, London; $\frac{(1)}{(1)}$ Department of Health and Social Security (1976), 음 Sharing resources for health in England, HMSO, London; Fuchs, V R (1974), Who shall live?, Basico Books, New York; Hauser, M M (ed) (1972), 
The economics of medical care, Allen and Unwin, London; Knox, E G (1978), 'Principles of allocation of health care resources', fournal of epidemiology and community health, 32:1, 3-9; Mooney, G H (1977), The valuation of human life, Macmillan, London; Owen, D (1975), 'Why the health service must be rationed', Sunday Times, 12 Oct; West, P A (1973), 'Allocation and equity in the public sector: The hospital revenue allocation formula', Applied economics, 5: 3, 153-66.

2Department of Health and Social Security (1976). Prevention and health: everybody's business, HMSO, London, $\mathrm{p} 7$.

${ }^{3}$ In this account I combine the economist's problem of formulating a social welfare function with the political scientist's perception of public decisionmaking as an incremental technique. See, inter alia, the following: Arrow, K J (1963), Social choice and individual values, Yale University Press, New Haven (2nd ed); Braybrooke, D, and Lindblom, C E (1963), A strategy of decision: policy evaluation as a social process, Free Press, Glencoe; Dahl, R A, and Lindblom, C E (1976), Politics, economics and welfare, University of Chicago Press, Chicago (2nd ed); Davis, O et al (1966), 'Towards a theory of the budgetary process', American political science review, LX, 529-47; Dunsire, A (1975), Administration: the word and the science, Martin Robertson, London, pp r19-33; Judge, K (1978), Rationing social services, Heinemann, London; Klein, R (1974), 'Policy making in the National Health Service', Political studies, XXII, I-I4; Nath, S K (1968), $A$ reappraisal of welfare economics, Routledge, London; Rothenberg, J (196I), The measurement of social welfare, Prentice-Hall, Englewood Cliffs, NJ; Wildavsky, A (1964), The politics of the budgetary process, Little Brown, Boston.

${ }^{4}$ Throughout this article I leave aside problems implicit in the use of morbidity indicators as criteria for the performance of health services. Naturally the community, that is the political process, must make some judgement about the priority it assigns to reductions in morbidity as against reductions in mortality.

${ }^{5}$ Correa, H (1967). 'Health planning', Kyklos, 20, 909-23. This article is discussed in Ruderman, A P 'General economic considerations' in Reinke, W A (ed) (1972), Health planning: qualitative aspects and quantitative techniques. John Hopkins University School of Hygiene and Public Health, Baltimore, pp 96-137.

${ }^{6}$ Foot, P (1967). 'The problem of abortion and the doctrine of the double effect', Oxford review, 5, 5-15.

'Calabresi, G (1965). 'The decision for accidents: an approach to the nonfault allocation of costs', Harvard law review, 78: 4, 713-45; 'Reflections on medical experimentation in humans' in Freund, $\mathbf{P}$ (ed) (1972), Experimentation with human subjects. Allen and Unwin, London, pp 178-96; Fried, C (1970), An anatomy of values, Harvard University Press, Cambridge, Mass., Chap. XII; Glover, J (1977), Causing death and saving lives, Penguin, Harmondsworth, pp 210-13; Mackie, J L (1977), Ethics, Penguin, Harmondsworth, pp 195-96; Mooney, G H (1977), The valuation of human life,
Macmillan, London, pp 80-82; Schelling, T C (1968), 'The life you save may be your own' in Chase, S B (ed), Problems in public expenditure analysis, Brookings, Washington. Reprinted in Cooper, M H and Culyer, A J (eds), (1973) Health economics. Penguin, Harmondsworth.

${ }^{8}$ Calabresi, 'The decision for accidents', p 716 .

${ }^{\circ}$ The artificial heart assessment panel, National Heart and Lung Institute, 'The totally implantable artificial heart: economic, ethical, legal, medical, psychiatric, and social implications' in Veatch, $R \mathbf{M}$, and Branson, R (1976), Ethics and health policy, Ballinger, Cambridge, Mass., Chap. 14, pp 234-35.

${ }^{10} \mathrm{Cf}$. Mooney (1977). The valuation of human life, $\mathrm{pp}$ 80-81.

${ }^{11} C f$. Sinclair, C, Manstrand, P, and Newick, P (1972). Innovation and human risk. Centre for the study of io industrial innovation, London, p 2 r.

${ }^{12}$ See Calabresi, 'Reflections on medical experimentation in humans', pp 179-84.

${ }^{13}$ The phrase was used by Pigou.

${ }^{14}$ Mishan, E J (1975). Cost-benefit analysis, p 306. Allen and Unwin, London.

${ }^{15} \mathrm{Cf}$. Fried, C, An anatomy of values, $\mathrm{p} 2 \mathrm{I}$ I.

${ }^{16} \mathrm{Cf}$. Fried, C, An anatomy of values, pp 215-16.

${ }^{17}$ Marshall, A (196I). Principles of economics, Macmillan, London (9th ed), pp II9-23; Pigou, A C (1960), The economics of welfare, Macmillan, London (4th ed), pp 24-26.

${ }^{18} C f$. Dworkin, $\mathrm{R}$ (1977). Taking rights seriously, Duckworth, London, pp 184-205; Hart, H L A (1955), 'Are there any natural rights ?' Philosophical review, 64, 175-91; Reprinted in Quinton, A (1967), (ed), Political philosophy, OUP, London; Nozick, R (1974), Anarchy, state and utopia, Blackwell, ¿ Oxford, pp 26-53; Rawls, J (1972), A theory of $\overrightarrow{\vec{B}}$ justice, OUP, London, pp I75-83, 446-52; Scanlon, 号 T M (1978), 'Rights, goals and fairness' in Hampshire, S (ed), Public and private mortality, CUP, Cambridge.

${ }^{19} \mathrm{Cf}$. McGloskey, H J (1975). 'The right to life', Mind, 84: 335, 403-25.

${ }^{20}$ Hohfeld, W N (1923). Fundamental legal conceptions. Yale University Press, New Haven.

${ }^{21} \mathrm{Cf}$. Anscombe, G E $\mathrm{M}$, 'Who is wronged ?', Oxford Review, 5, 16-17.

${ }^{22}$ Is this a Sorites paradox? It seems to be. Eubulides 윽 once proposed that there can be no such thing as a heap of sand since one grain does not make a heap and adding one grain is never enough to convert a non-heap into a heap. Is the paradox vicious ? It is $\sigma$ in the version of Eubulides, since there the con- $N$ cepts we apply to understand a physical system $N$ lead to conclusions which are in contradiction with $\omega$ our observation of the same physical system. To understand a physical system we need some iso- 0 morphism between the world and our conceptual $\overparen{\Phi}$ scheme; but the Sorites paradox suggests that the $\stackrel{\mathcal{O}}{+}$ assumption of an isomorphism will lead us into 0 falsity. However, the same viciousness is not $\bar{O}$ apparent in the analysis of moral reasoning: for in $\mathbb{D}$ that case we have just our conceptual scheme; there $\overrightarrow{\mathbb{D}}$ are no observations to conflict with the results of $\varnothing$ our analysis.

${ }^{23} \mathrm{Cf}$. Taurek, J M (1977). 'Should the numbers count ?', Philosophy and public affairs, 6: 4, 293-316. 
${ }^{24}$ Parfit, D (1978). 'Innumerate ethics', Philosophy and public affairs, 7: 4, 287-88.

${ }^{25} \mathrm{Cf}$. Roupas, T G (1978). 'The value of life', Philosophy and public affairs, 7: 2, I54-55.

${ }^{26}$ For the survival lottery see: Harris, J (1975). 'The survival lottery', Philosophy, 50, 8I-7; Singer, P (I977), 'Utility and the survival lottery', Philosophy; 52, 218-22; Trammell, R L, and Wren, T E (I977), 'Fairness, utility and survival', Philosophy, 52, 33I-37.

${ }^{27} \mathrm{Cf}$. Singer. 'Utility and the survival lottery'.

${ }^{28}$ Among many references see, Olson, $M$ (1965). The logic of collective action, Harvard University Press, Mass.

${ }^{29}$ Ross, W D (1930). The right and the good, Clarendon, Oxford, pp 2 I-22.

${ }^{30}$ There are, it would seem, strong biological motives inclining individuals to lay down their own lives for the benefit of others, but they operate most forcibly when those involved are related to one another. Recall Haldane's remark that he would be prepared to lay down his life for two of his brothers or eight of his cousins. This is the theory of 'kin selection': individual altruism will, in certain circumstances, confer a selective advantage on a gene contained in an animal group particularly when members of the group are closely related. See Maynard Smith, J (1975), The theory of evolution, Penguin, Harmondsworth (3rd ed), pp I78ff.
${ }^{31}$ Trammell, $R$ L (1975). Saving life and taking life fournal of philosophy, 72: 5, 13I-37. Whether thenc. is a significant logical or moral difference betweef taking life and allowing to die is a much discusse question. See, inter alia: Anscombe, G E M (1958 fo Modern moral philosophy, Philosophy, 33: I2 I-I9; Dinello, D (1971), On killing and letting die Analysis, 31: 3, 83-86; Reschels, J (1979), Killin and starving to death, Philosophy, 54, 159-71.

3226 F. Cas. 360 (No. 15,383) (CCED Pa 1842). Diso cussed in Ramsey, $\mathrm{P}$, The patient as person, Yafe University Press, New Haven, 1970, p 253, from which this reference is taken.

${ }^{33} 14$ QBD 273 (1884), also discussed in Ramsey, Thes patient as person, $\mathrm{p} 253$, from which this reference is taken.

${ }^{34}$ Godwin, W (1976). Enquiry concerning political justice (edited I Kramnick), Penguin, Harmondsworths first published I798, p I70.

${ }^{35}$ Fried, C, An anatomy of values, $\mathrm{p} 19$.

${ }^{36}$ Fried, C (1974). Medical experimentation: Personas integrity and social policy. North-Holland, Amster= dam, pp 160-65.

${ }^{37}$ For a typically careful discussion of this doctrine, se Sidgwick, H (1891). The elements of politics, Macmillan, London, Chap. 10.

${ }^{38}$ Kendall, $R$ E (1977). The painful facts in Phillips $\mathrm{C} \mathrm{E}$, and Wolfe, J N (eds), Clinical practice and economics, Pitman Medical, Tunbridge Wellş pp 94-96. 